\title{
Factors that control heavy snowfalls in the eastern coast of Korea
}

\author{
Seoung Soo Lee ${ }^{1, *}$, Byung-Gon Kim ${ }^{2}$, Hyoung-Gu Nam ${ }^{2}$, Seong Soo Yum ${ }^{3}$, Yong-Sang Choi ${ }^{4}$, and \\ Chang-Hoon Jung ${ }^{5}$ \\ ${ }^{1}$ Earth System Science Interdisciplinary Center, University of Maryland, Maryland \\ ${ }^{2}$ Department of Atmospheric Environmental Sciences, Gangneung-Wonju National University, Gangneung, Gang-Won do, South \\ Korea \\ ${ }^{3}$ Department of Atmospheric Sciences, Yonsei University, Seoul, South Korea \\ ${ }^{4}$ Department of Environmental Science and Engineering, Ewha Womans University, Seoul, South Korea \\ ${ }^{5}$ Department of Health Management, Kyungin Women's University, Incheon, South Korea
}

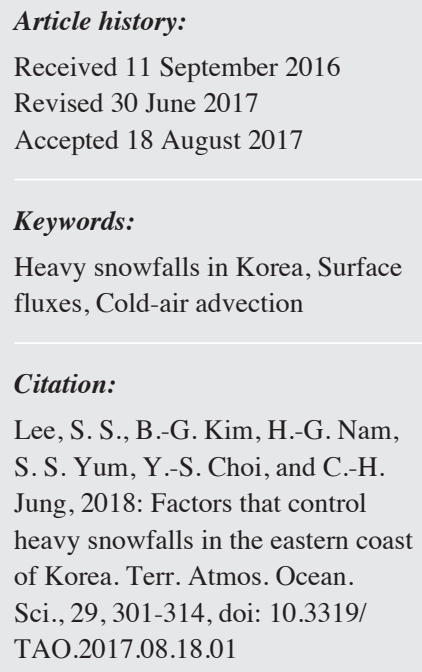

\begin{abstract}
This study examines mechanisms which control heavy snowfalls in the eastern coast of Korea. Previous observational studies have indicated that heavy snowfalls are caused by the advection of cold and dry air over the warm ocean off the eastern coast. Previous studies have not considered the effects of surface heat fluxes on heavy snowfalls. It is likely that the warm ocean produces strong surface heat fluxes that are able to invigorate convection and enhance precipitation. Motivated by this, this study examines not only the effect of the advection on heavy snowfalls but also that of surface heat fluxes and compare these two types of effects. In addition to this, this study looks into microphysical and dynamic processes which are associated with heavy snowfalls, considering that previous studies have not given us information on these processes. By running high-resolution simulations, this study finds that surface heat fluxes are a main driver of heavy snowfalls and the roles played by the advection in them are negligible. Surface heat fluxes induce strong updrafts and large deposition onto snow and cloud ice, which enables the efficient growth of snow and heavy snowfalls. This demonstrates that for better understanding of heavy snowfalls in the eastern coast of Korea, we have to better understand the surface processes that are linked to surface heat fluxes.
\end{abstract}

\section{INTRODUCTION}

The Yeongdong region in the eastern coast of Korea has been experiencing frequent heavy snowfalls. These events have been making substantial impacts on people in the region socially and economically. Observational studies demonstrated that these heavy snowfalls frequently accompany synoptic situations where cold-air outbreaks over the sea off the eastern coast of Korea occur. It is believed that these outbreaks bring low-level cold and dry air over to areas off the eastern coast of Korea. Based on this, previous studies have been focusing on a linkage between synoptic situations, the advection of cold and dry air and heavy snowfalls.

The previous studies have found that synoptic situations involving the Siberian High, which develops to oc-

\footnotetext{
* Corresponding author

E-mail:cumulss@gmail.com
}

cupy the sea off the eastern coast of Korea and northern Japan, and the Low system, which passes by the southern Korean Peninsula and is located along with the Siberian High, provide a favorable condition for the easterly flow over the Yeongdong region (Lee and Sung 2003; Park et al. 2009; Choi and Kim 2010). The low-level advection of cold and dry air from the Siberian High via the easterly flow over the relatively warm surfaces of the sea off the Yeongdong region can destabilize the atmosphere and invigorate ice clouds (or enhance the updraft speed in those clouds) over the ocean off the Yeongdong region, which generates heavy snowfalls (Seo and Jhun 1991; Ahn and Cho 1998; Kim and Kwon 2005). These previous studies that have examined heavy snowfall particularly in the eastern coast of Korea have been mostly based on observations and they have mainly discussed the stability in the air associated with the advection of cold and dry air. 
While focusing on the stability is a valuable first stepping stone to the understanding of the mechanisms that control heavy snowfalls, we may need to take additional attention to the surface processes such as surface heat fluxes as a next stepping stone. In this study, surface heat fluxes mean the sum of sensible-heat fluxes and latent-heat (or moisture) fluxes at the surface. The warm surfaces of the sea off the eastern coast of Korea are likely to produce high levels of surface heat fluxes. Considering that strong surface heat fluxes have been known to produce clouds with strong intensity or the high updraft speed (Houze 1993; Lee et al. 2008), these likely high levels of surface heat fluxes are in favor of the invigoration of clouds.

In fact, there are previous studies which have shown that surface heat fluxes play an important role in clouds and precipitation (including snowfalls) (e.g., Nakamura and Asai 1985; Yoshizaki et al. 2004; Lee et al. 2008, 2014). However, these studies have examined the effect of surface fluxes on rainfall and snowfalls in places other than the eastern coast of Korea and there have been lack of studies about the role played by surface fluxes in snowfalls in the eastern coast of Korea. Considering the strong dependence of the development of clouds and precipitation on regional climate (Houze 1993; Lee et al. 2008), it is difficult to apply the findings from those previous studies to the eastern coast of Korea. This merits the investigation of the effects of surface heat fluxes on clouds and snowfalls over the sea off the eastern coast of Korea. Considering a dearth of understanding of the role by surface fluxes in heavy snowfalls over the sea off the eastern coast of Korea, this investigation can potentially bring us an improvement in our comprehensive understanding of mechanisms that control heavy snowfalls in the eastern coast of Korea. For the comprehensive understanding, we also need to look into cloud dynamic and microphysical processes and feedbacks between them in invigorated clouds. However, it is difficult to identify these individual processes and associated feedbacks in observation data.

This study aims to identify the effect of surface heat fluxes on the invigoration of clouds and heavy snowfalls in the eastern coast of Korea by performing simulations with a large-eddy simulation (LES) framework. This study also compares this surface-flux effect to the effect of the advection of cold and dry air on the invigoration and heavy snowfalls through the modeling framework. This comparison will elucidate the role played by surface heat fluxes in the heavy snowfalls by giving us information of how important the effect of surface heat fluxes is as compared to the well-investigated effect of the advection on snowfalls over the sea off the eastern coast of Korea. Those simulations complement observational findings by showing us dynamic and microphysical features and associated feedbacks that are related to the invigoration and heavy snowfalls. Eventually, these simulations will enable us to combine the advection, surface fluxes and dynamic and microphysical features, which has been lacking in the previous studies of snowfalls in the eastern coast of Korea and will bring us a more complete picture of mechanisms that lead to heavy snowfalls.

\section{LES MODEL}

This study utilizes numerical simulations to fulfill its aim. The Advanced Research Weather Research and Forecasting (ARW) model (version 3.1.1) is adopted for the simulations. The ARW model, a three-dimensional nonhydrostatic compressible model, is used here as a LES model. Shortwave and longwave radiation parameterizations have been included in all simulations. The microphysical processes are represented by a double-moment bin-bulk scheme that uses bin-model-derived lookup tables for hydrometeor collection processes (Saleeby and Cotton 2004). A gamma size distribution with fixed breadth is assumed for hydrometeor size distributions. Cloud-droplet and ice-crystal nucleation also mimic a size-resolved approach (Lee et al. 2010). Aerosol is represented by a single scalar (number mixing ratio), the assumption of a fixed (tri-lognormal) size distribution and a fixed composition (ammonium sulfate) (see Table 1 for adopted parameters of the lognormal distribution). With this assumption, droplet nucleation is calculated based on predicted supersaturation. The cloud droplet nucleation parameterization of Abdul-Razzak and Ghan (2000, 2002), which is based on Köhler theory, is used. Aerosol particles with critical supersaturation smaller than the model-predicted supersaturation are activated to be droplets. During the simulation, aerosol is advected, diffused and processed. Through droplet or ice nucleation, aerosol mass is included in cloud liquid or cloud ice and is transferred to other species of hydrometeors through collection. Aerosol mass moves from the atmosphere to the surface when precipitating hydrometeors fall to the surface and aerosol mass is released from hydrometeors to the atmosphere when hydrometeors

Table 1. Aerosol size distribution parameters in this study: mode radius $r_{m i}(\mu m)$, standard deviation $\sigma_{i}$, and the ratio of number concentration in each mode to total number concentration $\mathrm{N}_{\mathrm{i}}$.

\begin{tabular}{ccc|ccc|ccc}
\hline \multicolumn{3}{c|}{ Nuclei Mode } & \multicolumn{3}{c|}{ Accumulation Mode } & \multicolumn{3}{c}{ Coarse Mode } \\
\hline $\mathrm{r}_{\mathrm{m} 1}$ & $\sigma_{1}$ & $\mathrm{~N}_{1}$ & $\mathrm{r}_{\mathrm{m} 2}$ & $\sigma_{2}$ & $\mathrm{~N}_{2}$ & $\mathrm{r}_{\mathrm{m} 3}$ & $\sigma_{3}$ & $\mathrm{~N}_{3}$ \\
\hline 0.008 & 1.6 & 0.55 & 0.034 & 2.1 & 0.44 & 0.47 & 2.2 & 0.0004 \\
\hline
\end{tabular}


evaporate or sublimate. The effects of aerosol, both unactivated and activated, on radiative heating (i.e., aerosol direct and semi-direct effects) are not taken into account.

\section{CASE DESCRIPTION AND NUMERICAL EXPERIMENTS}

\subsection{Control Run}

For the control run, a three-dimensional simulation of an observed cloud system in the planetary boundary layer (PBL) is performed over a 12-hr period. The cloud system is observed during a period between 03:00 LST (local solar time) and 15:00 LST 20 March 2013 at $\left(37.7^{\circ} \mathrm{N}, 128.7^{\circ} \mathrm{E}\right)$. During this 12 -hr period, soundings are obtained every $3 \mathrm{hrs}$ by radiosonde that is launched at $\left(37.7^{\circ} \mathrm{N}, 128.7^{\circ} \mathrm{E}\right)$.

Figure 1 shows a weather chart at 03:00 LST 20 March. This chart describes the synoptic condition at the surface and the observed cloud system is embedded in this synoptic condition. The site where the radiosonde is launched and the cloud system is observed is marked by a red rectangle in the Korean peninsula in Fig. 1. In this chart, the center of low pressure is located over the south of Korea, and continues to move to the southern part of Japan. Afterwards northeasterly winds are induced in the Yeongdong region (in and around the red rectangle) along with the expansion of the Siberian High to the East Sea from the morning of 20 March when the snowfall is initiated. This synoptic setting is quite common for the heavy snowfall episodes in Yeong- dong region (Lee and Sung 2003; Park et al. 2009; Choi and Kim 2010).

The radiosonde measures the soundings with the vertical resolutions of $\sim 10-20 \mathrm{~m}$. The first sounding (i.e., the initial potential temperature, equivalent potential temperature, humidity or water-vapor mixing ratio, saturation water-vapor mixing ratio, and horizontal wind) obtained by the radiosonde at 03:00 LST 20 March is depicted in Fig. 2. This first sounding is applied to the control run as initial conditions. Below $\sim 1 \mathrm{~km}$, there are gradual increases in potential temperature, followed by its rapid increases in a layer between $\sim 1$ and $\sim 1.5 \mathrm{~km}$ at 03:00 LST 20 March (Fig. 2a). Initial water-vapor mixing ratios decrease up to $\sim 1 \mathrm{~km}$, followed by its rapid increases in the layer between $\sim 1$ and $\sim 1.5 \mathrm{~km}$ (Fig. 2b). This indicates that initially the PBL whose top is $\sim 1 \mathrm{~km}$ is capped by the warm and humid layer between $\sim 1$ and $\sim 1.5 \mathrm{~km}$. Below $\sim 1 \mathrm{~km}$ or in the PBL, initial wind is northeasterly, however, in a layer between $\sim 1$ and $\sim 1.5 \mathrm{~km}$, there is a transition from the northeasterly wind to the southwesterly wind (Fig. 2c).

Large- or synoptic-scale forcings of potential temperature and humidity are applied to the simulation (i.e., the control run) every time step. For this application, first, largescale forcings are obtained by calculating the tendencies (or the rate of changes) in potential temperature and humidity with time among the collected soundings by the radiosonde and then the tendencies are interpolated to every time step. Here, we assume that soundings and their evolution

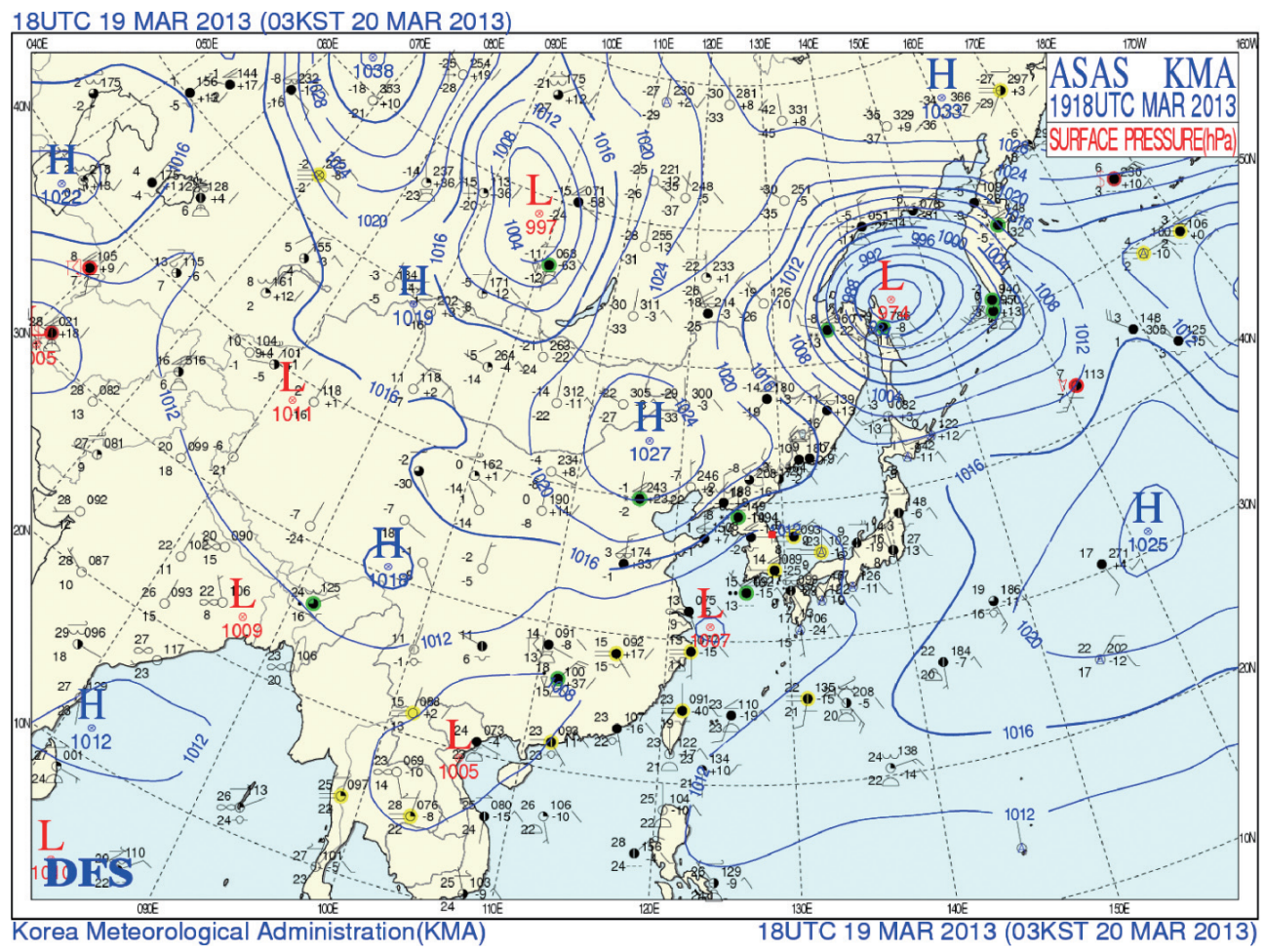

Fig. 1. Weather chart that describes the surface synoptic condition at 03:00 LST 20 March. 
(a)

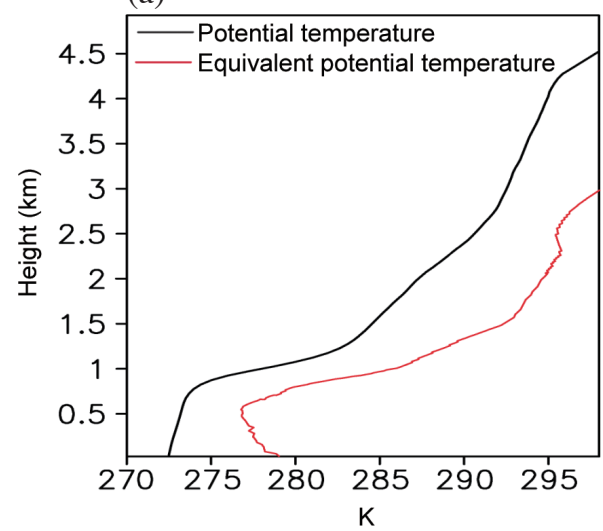

(b)

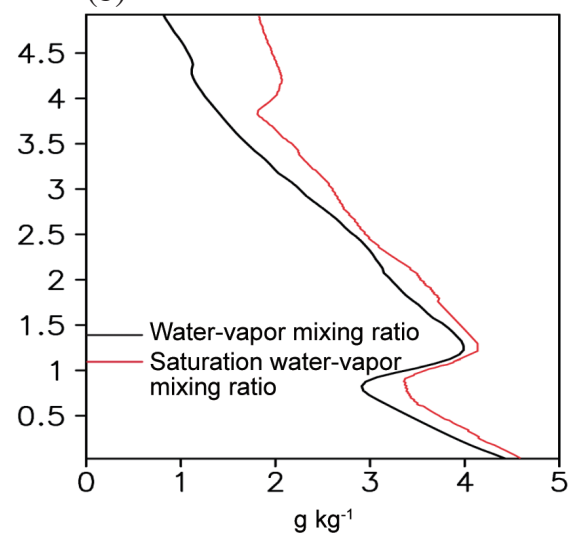

(c)

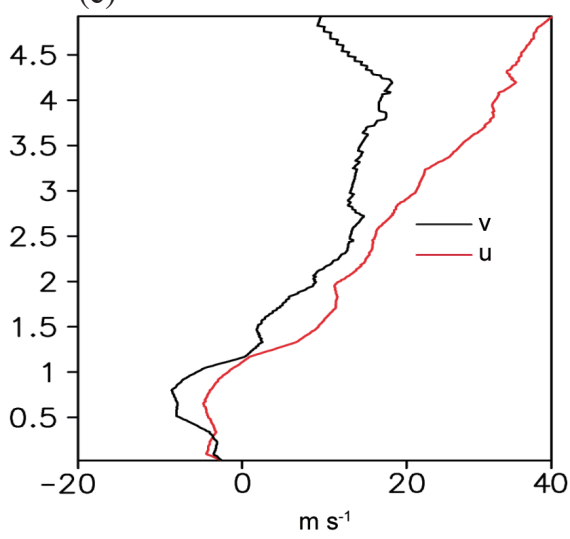

Fig. 2. Vertical distribution of initial (a) potential temperature $(\mathrm{K})$ and equivalent potential temperature (K), (b) water-vapor mixing ratio $\left(\mathrm{g} \mathrm{kg}^{-1}\right)$ and saturation water-vapor mixing ratio $\left(\mathrm{g} \mathrm{kg}^{-1}\right)$ and (c) speeds of $\mathrm{u}$ (or east-west; $\mathrm{m} \mathrm{s}^{-1}$ ) and $\mathrm{v}$ (or north-south; $\mathrm{m} \mathrm{s}^{-1}$ ) components of wind.

represent the synoptic- (or large-scale) environment and its evolution, respectively. This method of modeling cloud systems was used for the LES comparison study by vanZanten et al. (2011). The details of the procedure for applying largescale forcings are described in Donner et al. (1999). The horizontal momentum is damped to observed values, following Xu et al. (2002). Solid lines in Figs. 3a and b show the time- and domain-averaged observed large-scale forcings or large-scale advective tendencies of potential temperature and humidity or water-vapor mixing ratio, respectively.

The negative large-scale forcings of potential temperature exist below $\sim 3 \mathrm{~km}$ (Fig. 3a), while negative forcings of water-vapor mixing ratio exist throughout the vertical domain in Fig. 3b. In particular, the magnitude of the negative forcings is at its maximum in the layer between $\sim 1$ and $\sim 1.5 \mathrm{~km}$. This eventually reduces stability in the layer below $\sim 1.5 \mathrm{~km}$ and favors the development of convective cumulus clouds that are described in the following sections. In this study, the advection of cold and dry air is represented by the negative large-scale (or synoptic-scale) forcings of temperature and humidity. This is because the negative forcings are the negative advective tendencies that represent reducing temperature and humidity due to the advection of cold and dry air.

Surface temperature, surface latent and sensible heat fluxes are predicted by using Noah land surface model (Chen and Dudhia 2001). The simulated time- and domain-averaged surface latent and sensible heat fluxes are 175 and $145 \mathrm{~W} \mathrm{~m}^{-2}$, respectively. The observed and simulated surface temperatures are between $\sim 0$ to $\sim-4^{\circ} \mathrm{C}$ during the 12 -hr period. The horizontal domain length is set at $30 \mathrm{~km}$ in both directions to capture mesoscale structures of the cloud system while the vertical domain length is set at $5 \mathrm{~km}$. The horizontal grid length is $100 \mathrm{~m}$ and the vertical grid length is $50 \mathrm{~m}$. Periodic boundary conditions are applied at the horizontal boundaries. The control run adopts an initial background aerosol num- ber concentration of $2500 \mathrm{~cm}^{-3}$ over the whole simulation domain, which is a typical value over the ocean around the eastern coast of Korea (Kim et al. 2014).

\subsection{Additional Runs}

This study aims to gain a clear understanding of how surface heat fluxes affect clouds and snowfall in the eastern coast of Korea. To fulfill this aim, we can apply a variety of methodologies that involve various sensitivity tests of surface heat fluxes to this study. Among the methodologies, as a preliminary step, it is best to compare a standard simulation (i.e., the control run) where surface heat fluxes affect clouds and snowfall to an idealized simulation where surface fluxes do not affect them. Upward surface fluxes tend to increase humidity and temperature around the surface and thus to increase the instability, while downward fluxes tend to reduce humidity and temperature around the surface and thus to reduce the instability. Hence, upward and downward surface fluxes both are important in affecting the stability, clouds, and snowfall. When surface heat fluxes are zero or have no downward and upward components, surface heat fluxes cease to affect stability, clouds, and snowfall. Based on this, to examine roles played by surface heat fluxes in results from the control run, the control run is repeated with surface heat fluxes that are not predicted and set at $0 \mathrm{~W} \mathrm{~m}^{-2}$. This repeated run is referred to as the "zero-flux run" that acts as the idealized simulation. In this study, contrast between clouds and snowfall in the presence (or non-zero values) of upward and downward surface fluxes (as in the control run) and those in the absence (or zero values) of those fluxes (as in the zero-flux run) is defined to be the effect of surface fluxes on clouds and precipitation. We believe that this contrast is one of the most effective ways to elucidate roles played by surface heat fluxes in clouds and precipitation.

To see the effect of the low-level advection of cold 


\section{Large-scale forcings}

(a) Potential temperature

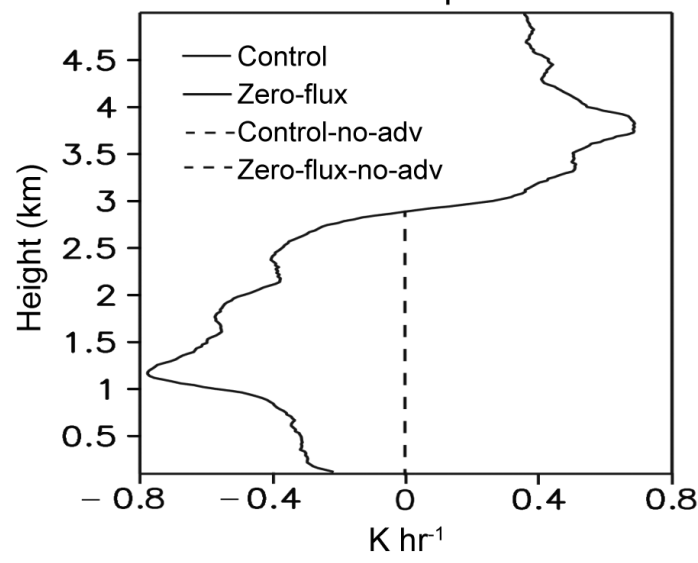

Humidity

(b) (water-vapor mixing ratio)

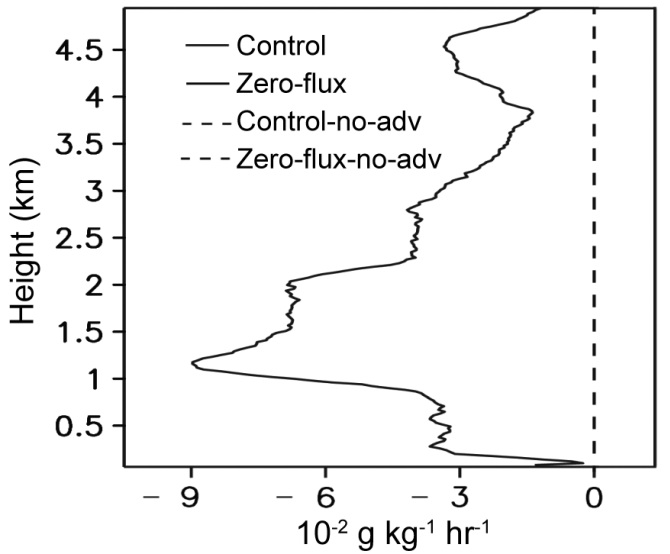

Fig. 3. Large-scale forcings of (a) potential temperature $\left(\mathrm{K} \mathrm{hr}^{-1}\right)$ and (b) humidity or water-vapor mixing ratio $\left(10^{-2} \mathrm{~g} \mathrm{~kg}^{-1} \mathrm{hr}^{-1}\right)$.

and dry air on heavy snowfall, the control run and the zeroflux run are repeated. The repeated control run is referred to as the control-no-adv run, while the repeated zero-flux run is referred to as the zero-flux-no-adv run. The negative large-scale forcings of temperature and humidity, which represent the advection of cold and dry air, is set at zero for these repeated simulations as shown in Fig. 3. However, the identical positive temperature forcings above $\sim 2.8 \mathrm{~km}$ in the control run (as shown in Fig. 3) are applied to these repeated runs. In this study, contrast between clouds and snowfall with the non-zero negative large-scale forcings of temperature and humidity (as in the control run and the zero-flux run) and those with the zero large-scale forcings of temperature below $\sim 2.8 \mathrm{~km}$ and humidity throughout the vertical domain (as in the control-no-adv run and the zeroflux-no-adv run) is defined to be the effect of the low-level advection of cold and dry air on clouds and precipitation. This effect is compared to that by surface heat fluxes to identify relative importance of the effect of the advection to the effect of surface fluxes. Summary of simulations in this paper is shown in Table 2.

Among changes in temperature and humidity in air, it is well-known that surface heat fluxes are most sensitive to those changes in air that contacts the surface. Hence, alteration, induced by the advection of cold and dry air, on temperature and humidity and their contrast between air (that contacts the surface) and the surface effectively alters surface heat fluxes. In this study, advection-induced changes not only in cloud variables (e.g., hydrometeor mixing ratio, precipitation and updrafts) but also in the surface variables (e.g., surface fluxes) are considered to be parts of the effect of the advection. By the same token, the subsequent changes in the cloud or atmospheric variables that are induced by the presence of surface heat fluxes are considered to be parts of the effect of surface heat fluxes. Hence, in this study, the effect of surface heat fluxes and the advection, respectively, is considered to be a trigger effect that is generated by the presence of surface fluxes and the advection, respectively, and induces subsequent changes in variables of interest whether they are in the atmosphere or at the surface.

\section{RESULTS}

\subsection{Control Run}

Figure 4 shows the time series of the domain-averaged precipitation rates at the surface. In this study, the first $3 \mathrm{hrs}$ of the simulation period between 03 and 06 LST are considered to be a spin-up period. Thus, in all of the simulations in this study, the analyses and discussion of the results are performed over the last $9 \mathrm{hrs}$ of the simulation period between 06 and 15 LST 20 March, unless otherwise stated. The simulated precipitation rate in the control run follows the observed counterpart well, which demonstrates that the control run is performed reasonably well. For the case simulated, precipitation that reaches the surface is composed of snow and rain. Here, to calculate both the simulated and observed precipitation rates, using the density of snow particles, we convert the amount or depth of snow reaching the surface into the amount or depth of equivalent liquid water and this amount is added to the amount of rain reaching the surface.

Figure 5 shows the time series of the observed and simulated percentage portion of snow in precipitation. As seen in Fig. 5, overall, snow is a dominant form of precipitation, since the portion of snow is always above $96.5 \%$; on average, the simulated snow accounts for $98.5 \%$ of the precipitation mass over the 12-hr simulation period. Also, in Fig. 5, we see that the simulated snow portion in the control run follows the observed counterpart well. Since the non-zero snow portion exists throughout the simulation period which lasts $12 \mathrm{hrs}$, the duration time of snow is $12 \mathrm{hrs}$. 
Table 2. Summary of simulations.

\begin{tabular}{ccc}
\hline Simulations & Surface fluxes & Negative low-level advection \\
\hline Control run & Predicted & Present \\
Zero-flux run & Set at 0 & Present \\
Control-no-adv run & Predicted & Set at 0 \\
Zero-flux-no-adv run & Set at 0 & Set at 0 \\
\hline
\end{tabular}

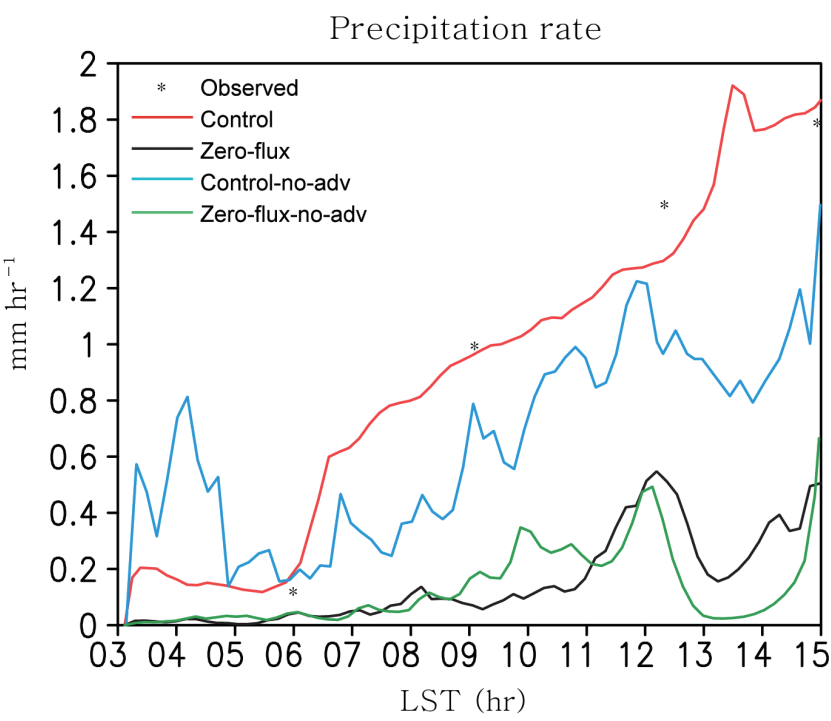

Fig. 4. Time series of the domain-averaged precipitation rates $\left(\mathrm{mm} \mathrm{hr}^{-1}\right)$

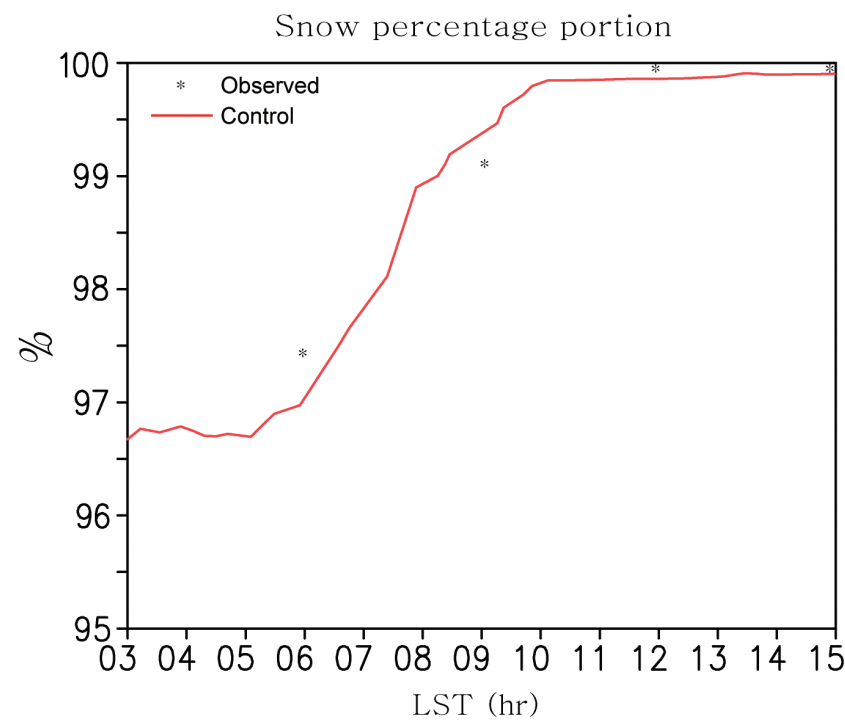

Fig. 5. Time series of the observed and simulated percentage portion of snow in precipitation for the control run.
Considering that the density of snow particles is $\sim 10$ times smaller than that of raindrops and snow accounts for nearly $100 \%$ of precipitation mass reaching the surface, the rate of increase in the depth or amount of the surface snow, which is not converted into equivalent liquid water, is $\sim 10$ times greater than precipitation rate in Fig. 4 with fairly good approximation. For example, the maximum precipitation rate at 13:30 LST is $1.9 \mathrm{~mm} \mathrm{hr}^{-1}$ in the control run and this corresponds to the increase rate of snow depth, which is $\sim 1.9 \mathrm{~cm} \mathrm{hr}^{-1}$. Based on this, the calculated domain-averaged accumulated depth of snow (not converted into equivalent liquid water) over the 12-hr simulation period is $\sim 15 \mathrm{~cm}$ in the control run and this $15-\mathrm{cm}$ depth is in good agreement with observed depth.

In the following parts of this paper, due to the fact that snow accounts for nearly $100 \%$ of precipitation mass reaching the surface, we use the term "snowfall rate" instead of "precipitation rate". Figures $6 \mathrm{a}$ and $\mathrm{b}$ show the snapshots of cloud-liquid and cloud-ice mass concentration $\left(\mathrm{g} \mathrm{m}^{-3}\right)$, respectively, in the control run. These snapshots are obtained over the west-east direction and at $15 \mathrm{~km}$ in the north-south direction. They are at 13:30 LST which is the time of the maximum snowfall rate and hence, represent clouds at their mature stage. As seen in Fig. 6, clouds are typically cumulus clouds which are trapped in the PBL whose tops are around $1.6 \mathrm{~km}$. The cores of these clouds occupy a portion of the domain and thus cause the inhomogeneous distribution of cloud properties such as cloud mass. In both Figs. 6a and b, the cores are defined as areas which have hydrometeor mixing ratios above $\sim 0.03 \mathrm{~g} \mathrm{~m}^{-3}$. In Fig. $6 \mathrm{~b}$, there are significant non-zero cloud-ice mixing ratios between the cores. However, in Fig. 6a, there are no significant cloud-liquid mixing ratios between the cores. Lower density of cloud-ice particles than that of cloud-liquid particles enables more efficient detrainment of cloud-ice particles from cores to places between them than that of cloud-liquid particles. In addition, the basic thermodynamics indicates that the water-vapor saturation level is higher for cloud liquid than for cloud ice, when cloud liquid and cloud ice experience a similar temperature. Hence, when cloud liquid and cloud ice are detrained to sub-saturated areas (between the cores) that has a similar temperature at each altitude, cloud-ice particles survive sublimation more efficiently as compared to cloud-liquid particles that survive evaporation. This contributes to the presence of the significant mass of cloud-ice particles between the cores in tandem with the more efficient detrainment of cloud-ice particles.

Figure 7 shows the spatial distribution of snowfall rate at the surface (represented by the shaded field) and the windvector field at the altitude of $50 \mathrm{~m}$ (represented by arrows) in the control run at 13:30 LST. Remember that 13:30 LST is the time when the maximum snowfall rate occurs, hence, the spatial distribution of snowfall rate at 13:30 LST can represent the situation with heavy snowfall better than that at other times. In Fig. 7, the white line marks the coastal line 
and the white rectangle marks the site where the radiosonde is launched and the cloud system is observed. The land area is located on the left-hand side of the line, while the sea area is located on the right-hand side of the line. Here, we see that the spatial distribution of snowfall is inhomogeneous; some of areas produce the snowfall rates that are $\sim 3$ times higher than those in other areas. Above-mentioned inhomogeneous spatial distributions of cloud properties in the PBL cumulus clouds cause the inhomogeneous distribution of snowfall. This is contrary to the situation in stratus clouds, since in general, the spatial distribution of stratus clouds and associated snowfall is homogeneous. Figure 7 also indicates that generally wind is northeasterly (as also shown by Fig. 1) and the northeasterly wind brings cold and dry air from areas that are located at the north of the study domain to the study domain.

Figure 8 depicts the spatial distribution of the cloud reflectivity observed by the Geostationary Operational Environmental Satellite (GOES) at 12:00 LST around the mature stage of the system in the study area. The reflectivity here is defined to be the ratio of the reflected radiative flux by an object to the incident radiative flux on it (Liou 2002) and thus unitless. The GOES provides cloud data every $3 \mathrm{hrs}$ over the study area. For Fig. 8, we select cloud data from the GOES at 12:00 LST which is closest to 13:30 LST (at which Fig. 7 is obtained). Since wind is mainly northeasterly, the cloud system moves southwestward while preserving its overall pattern, in particular between 12:00 LST and 13:30 LST. Hence, as compared to the cloud system (represented by the reflectivity) in Fig. 8, Fig. 7 shows the cloud system after it moved southwestward between 12:00 LST and 13:30 LST. Figure 8 demonstrates that the spatial distribution of the cloud reflectivity has high-level inhomogeneity, which is a typical characteristic for convective clouds such as cumulus clouds as discussed above. The retrieved cloudtop heights from the GOES data at 12:00 LST are between 1.2 and $1.4 \mathrm{~km}$ and these heights are consistent with the simulated counterparts. Since cloud-base heights are generally $\sim 200 \mathrm{~m}$, cloud depths are between 1.0 and $1.2 \mathrm{~km}$.

Figure 9 shows the time series of the domain-averaged water path of hydrometeor classes over the simulation period in the control run. Among the five classes of hydrometeors, snow mass is the largest, while cloud-ice mass is the second largest. As compared to snow and cloud-ice mass, liquid mass (i.e., cloud-liquid and rain mass) is negligible. Graupel mass is also negligible. Unlike the situation in deep convective mixed-phase clouds (particularly, during the summer time) where graupel accounts for a significant portion of cloud mass, graupel accounts for a very small portion of cloud mass as does cloud liquid and rain in the simulated PBL mixed-phase cumulus clouds. This is because deep convective clouds involve a much thicker cloud layer below the freezing level, much stronger updrafts, and thus a much greater amount of cloud liquid (relative to ice particles) as a source of riming on ice particles and producing more graupel than the PBL mixed-phase cumulus clouds. Figure 10a shows the vertical distributions of the time- and domain-averaged hydrometeor mass density in the control run. Consistent with what is seen in Fig. 9, snow and cloud ice account for the largest portion of cloud mass, while liquid and graupel mass account for the smallest portion of cloud mass.

The analysis on the budget of snow (which has the largest mass) shown in Table 3 indicates that snow is mainly produced by depositional growth of snow. Accretion of cloud ice by snow (or aggregation of ice crystals by snow particles) and autoconversion of cloud ice to snow also play an important role in the production of snow, however, their role is minor as compared to the depositional growth.

\section{(a)}

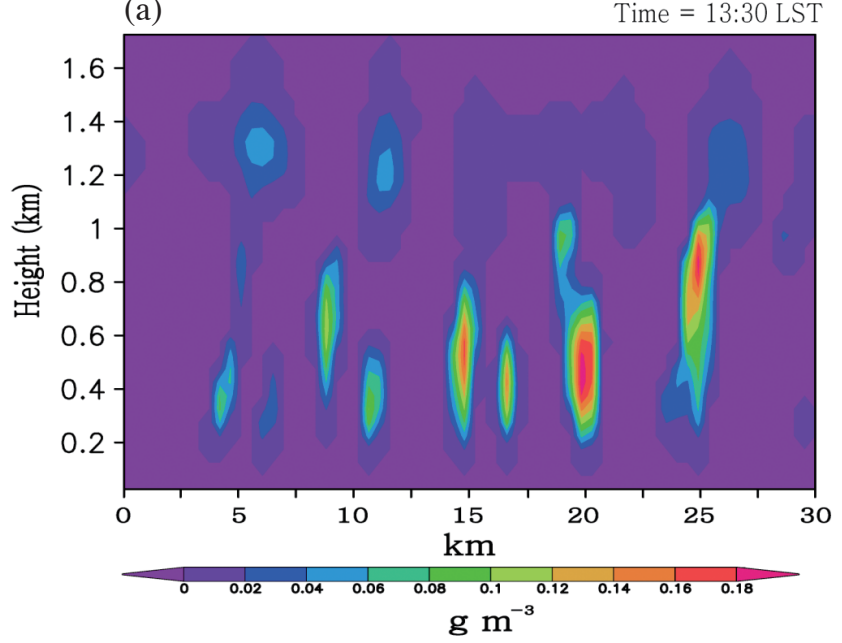

(b)

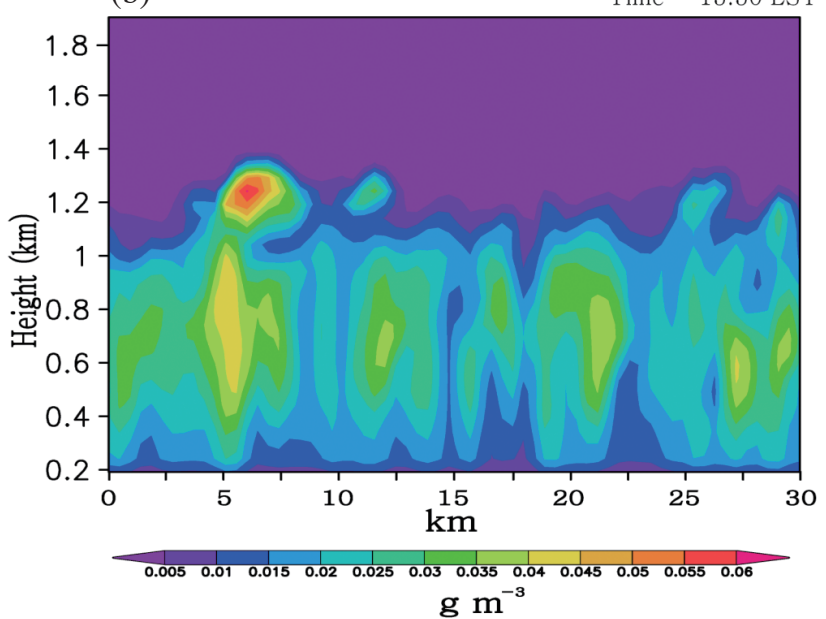

Fig. 6. Spatial distributions of (a) cloud-liquid mass density $\left(\mathrm{g} \mathrm{m}^{-3}\right)$ and (b) cloud-ice mass density $\left(\mathrm{g} \mathrm{m}^{-3}\right)$ over the west-east direction and at $15 \mathrm{~km}$ in the north-south direction. They are obtained at 13:30 LST 20 March. 


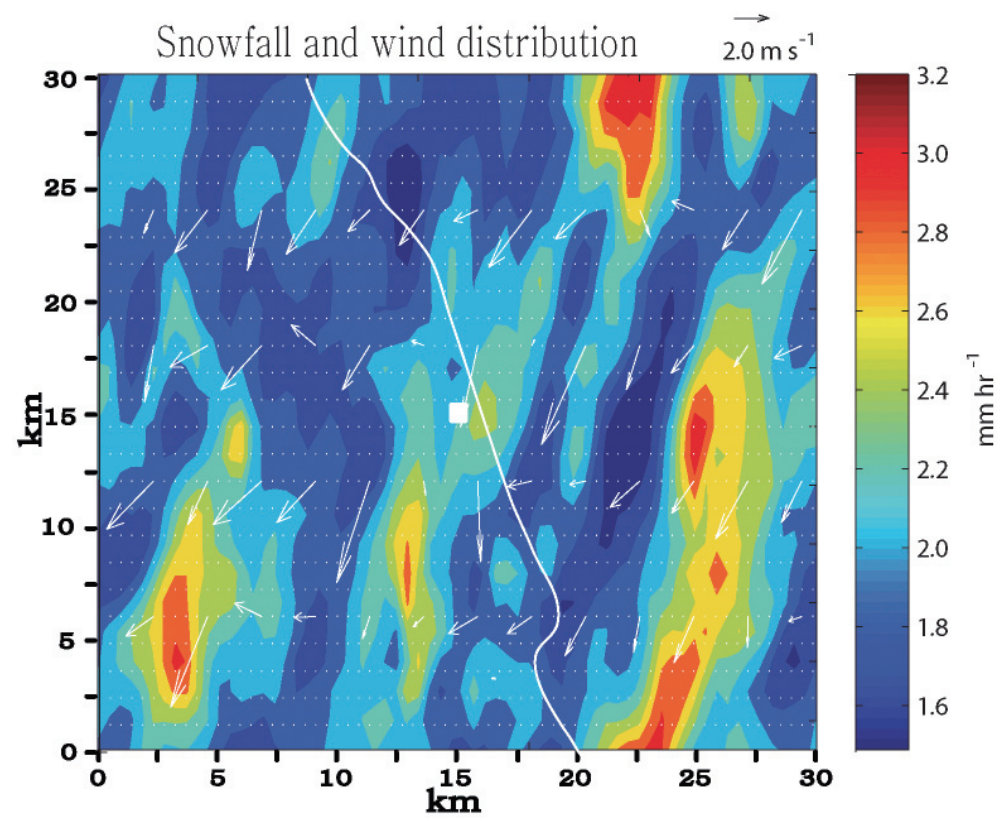

Fig. 7. Spatial distribution of snowfall rate at the surface (represented by the shaded field; $\mathrm{mm} \mathrm{hr}^{-1}$ ) and the wind-vector field at the altitude of 50 $\mathrm{m}$ (represented by arrows; $\mathrm{m} \mathrm{s}^{-1}$ ) in the control run at 13:30 LST 20 March. The white line marks the coastal line and the white rectangle marks the site where the radiosonde is launched and the cloud system is observed. The land area is located on the left-hand side of the line, while the sea area is located on the right-hand side of the line.

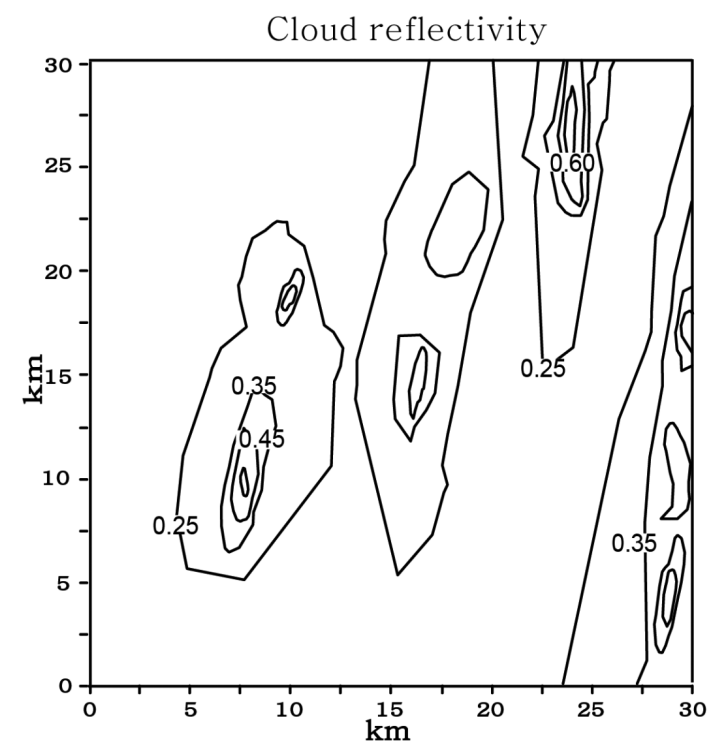

Fig. 8. Spatial distribution of cloud reflectivity which is unitless and observed by the Geostationary Operational Environmental Satellite (GOES) at 12:00 LST 20 March.

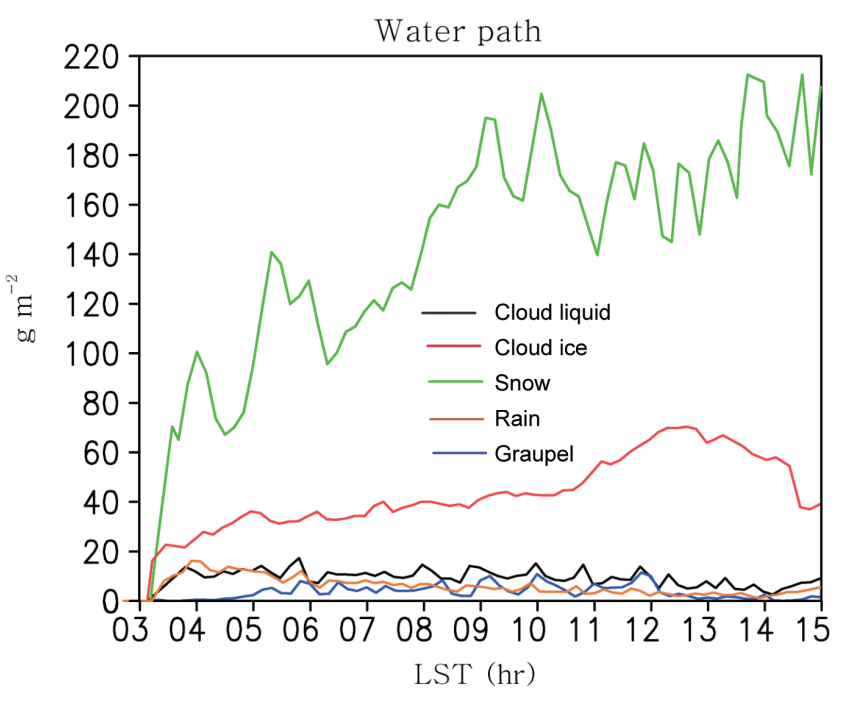

Fig. 9. Time series of the domain-averaged water path $\left(\mathrm{g} \mathrm{m}^{-2}\right)$ of each of hydrometeor classes. 


\section{Hydrometeor mass density}

(a)

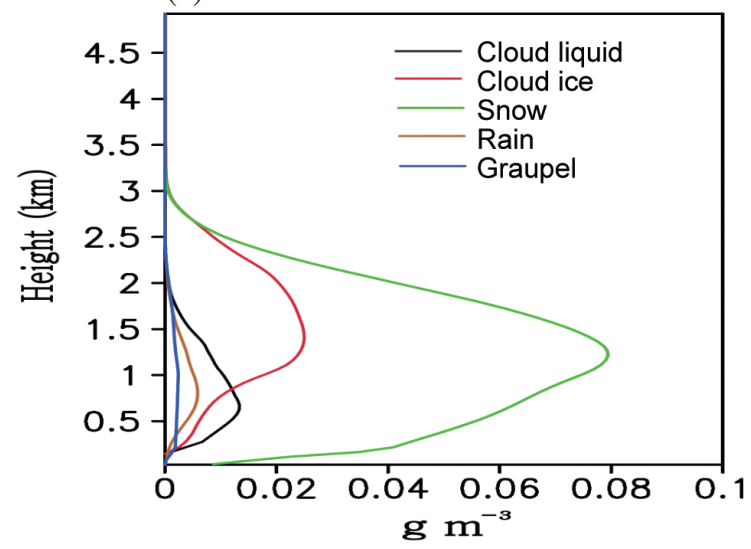

(b)

Zero-flux run

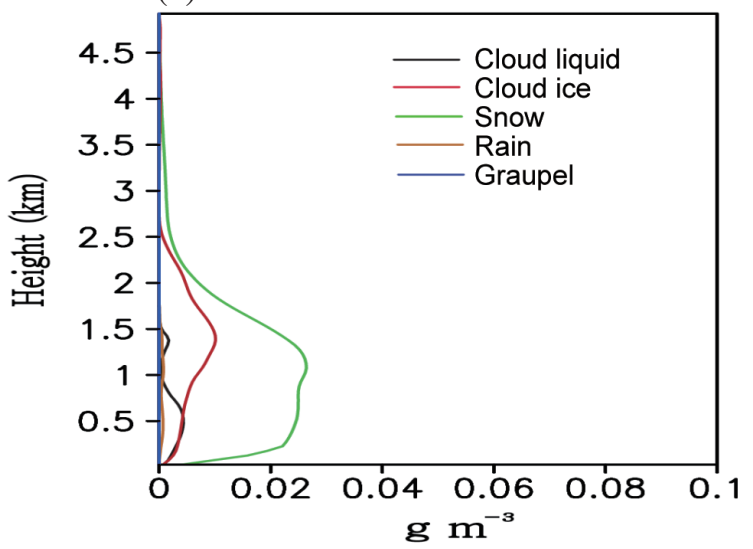

Fig. 10.Vertical distributions of the time- and domain-averaged mass densities $\left(\mathrm{g} \mathrm{m}^{-3}\right)$ of each of hydrometeor classes for (a) the control run and (b) the zero-flux run.

Table 3. Accumulated sources and sinks of snow mass, averaged over the domain.

\begin{tabular}{|c|c|c|c|c|}
\hline & Control & Zero-flux & Control-no-adv & Zero-flux-no-adv \\
\hline \multicolumn{5}{|c|}{ Snow sources $\left(10^{-4} \mathrm{~g} \mathrm{~m}^{-3} \mathrm{hr}^{-1}\right)$} \\
\hline Deposition of water vapor onto snow & 276 & 60 & 190 & 55 \\
\hline Accretion of cloud liquid by snow & 11 & 3 & 8 & 2 \\
\hline Autoconversion of cloud ice to snow & 53 & 11 & 39 & 9 \\
\hline Accretion of cloud ice by snow & 100 & 15 & 73 & 13 \\
\hline Accretion of cloud ice by rain to form snow & 23 & 4 & 17 & 4 \\
\hline Accretion of cloud ice by rain to form snow & 2 & 1 & 1 & 1 \\
\hline \multicolumn{5}{|c|}{ Snow Sinks $\left(10^{-4} \mathrm{~g} \mathrm{~m}^{-3} \mathrm{hr}^{-1}\right)$} \\
\hline Sublimation of snow & 435 & 86 & 307 & 78 \\
\hline Melting of snow & 3 & 1 & 2 & 1 \\
\hline
\end{tabular}

\subsection{Zero-Flux Run}

Figure 4 shows that snowfall rates decrease substantially with surface fluxes removed as compared to those in the control run. The time- and domain-averaged snowfall rate in the zero-flux run is $\sim 8$ times smaller than that in the control run. With surface fluxes removed in the zero-flux run, the vertical-velocity variance decreases substantially (Fig. 11a). The time- and domain-averaged vertical-velocity variance is $0.31 \mathrm{~m}^{2} \mathrm{~s}^{-2}$ in the control run, while it is $0.07 \mathrm{~m}^{2} \mathrm{~s}^{-2}$ in the zero-flux run. Hence, the vertical velocity is $\sim 4$ times smaller in the zero-flux run as compared to that in the control run.

Figure $11 \mathrm{~b}$ shows the vertical distribution of the timeand domain-averaged updraft speed. Comparisons between Figs. 11a and b demonstrate that the qualitative nature of differences in the updraft speed among the simulations is not different from that in the vertical-velocity variance. Hence, whether we focus on the updraft speed or the vertical-velocity variance does not affect the qualitative nature of arguments in this study. In the following parts of this paper, we choose to focus on the vertical-velocity variance. This is based on the fact that most of studies for the PBL clouds with the LES framework adopt the vertical-velocity variance instead of the updraft speed, since the PBL clouds are strongly controlled by the turbulent motions.

Note that in general, the level of supersaturation is proportional to the level of the vertical-velocity variance, since greater vertical-velocity variance induces the greater expansion of ascending air parcels and their adiabatic cooling, according to classic cloud physics. Thus, the decreases in the vertical-velocity variance reduce the level of supersaturation (especially, with respect to ice particles that comprise most of hydrometeors in this study) that is a primary controlling factor for the determination of deposition; it is well-known that deposition is proportional to supersaturation with respect to ice particles (e.g., snow and cloud ice). This leads to significant reduction in deposition onto snow and cloud ice in the zero-flux run. The reduction in deposition onto 
(a) Vertical-velocity variance

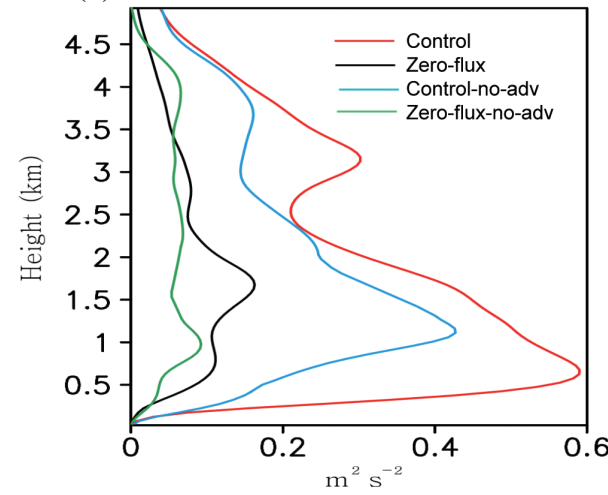

(b) Vertical velocity

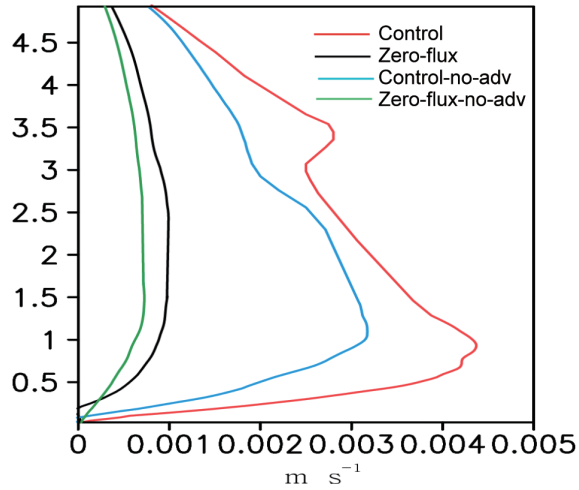

(c) Vertical-velocity variance

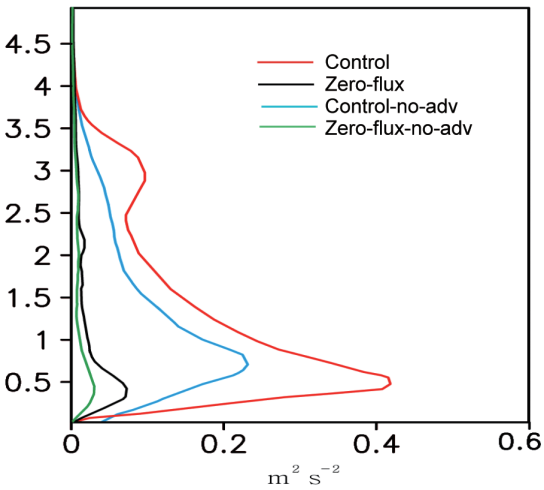

Fig. 11.Vertical distributions of the time- and domain-averaged (a) vertical-velocity variances $\left(\mathrm{m}^{2} \mathrm{~s}^{-2}\right)$ and (b) updraft speed ( $\left.\mathrm{m} \mathrm{s}^{-1}\right)$. $(\mathrm{c})$ is identical to (a) but averaged over the 3-hr pre-snowfall period as described in section 4.5.

cloud ice in turn leads to the considerably lowered amount of cloud ice (Figs. 10a and b). This eventually cuts down the amount of cloud ice collected by snow and autoconversion of cloud ice to snow and thus, contributes to the substantially decreased amount of snow which reaches the surface together with the lowered deposition onto snow in the zeroflux run (Table 3).

As shown in Fig. 12, the air temperature and humidity in the zero-flux run are much lower than those in the control run in places (including the atmosphere immediately above the surface) below $\sim 2.5 \mathrm{~km}$ due to the absence of surface heat fluxes. The temperature becomes similar between the two runs around $2.5 \mathrm{~km}$. The averaged variation of potential temperature per unit height in places between the surface and $2.0 \mathrm{~km}$ where most of clouds form is $3.3 \times 10^{-3}$ and 3.7 $\times 10^{-3} \mathrm{~K} \mathrm{~m}^{-1}$ in the control run and in the zero-flux run, respectively. We obtain the variation of potential temperature with height at grid points between the surface and $2.0 \mathrm{~km}$ and then we average the variation over those grid points to obtain the averaged variation. With the greater increases in potential temperatures (of the atmosphere where air parcels are embedded) with height, the overall temperature differences between given rising air parcels and the atmosphere are smaller. Thus, it is likely that these parcels are less buoyant or there is greater stability in the atmosphere below $\sim 2.0$ $\mathrm{km}$ in the zero-flux run than in the control run. In addition, when temperature around the surface is high, parcels start to rise around the surface with high temperature. Thus, for given temperatures of the atmosphere above the surface, the temperature difference between rising air parcels and atmosphere where these parcels are embedded can be large. This means that parcels are more buoyant and thus there is greater instability in the atmosphere. Hence, the lower temperature around the surface is also likely to make parcels less buoyant or make stability greater in the zero-flux run than in the control run.

The probable greater stability is confirmed by smaller convective available potential energy (CAPE) in the zeroflux run than in the control run. Note that CAPE is a representative measure of stability and smaller CAPE means greater stability. The time- and domain-averaged CAPE is 150.3 and $680.2 \mathrm{~J} \mathrm{~kg}^{-1}$ in the zero-flux run and the control run, respectively (Table 4). The averaged CAPE over the observed soundings is $673.3 \mathrm{~J} \mathrm{~kg}^{-1}$ which is just $\sim 1 \%$ smaller than that simulated in the control run. Hence, we believe that CAPE values are simulated reasonably well in this study. The lower CAPE produces the weaker updrafts in the zero-flux run than in the control run.

The zero-flux run indicates that although there is the well-known advection, when surface heat fluxes are absent, updraft, cloud mass and snowfall decrease substantially. This demonstrates that surface heat fluxes play an important role in the heavy snowfall.

\subsection{Control-No-Adv Run}

As seen in Fig. 4, when there is no low-level advection of cold and dry air, snowfall decreases in the control-no-adv run as in the zero-flux run as compared to that in the control run. However, the decrease in the control-no-adv run is not as large as in the zero-flux run. The domain-averaged cumulative precipitation (most of which is composed of snow) at the last time step in the control-no-adv run is $9.8 \mathrm{~mm}$ which is $66 \%$ of that (i.e., $14.7 \mathrm{~mm}$ ) in the control run, while it is $1.9 \mathrm{~mm}$ in the zero-flux run which is only $13 \%$ of that in the control run.

With the low-level advection of cold and dry air removed, the vertical-velocity variance decreases as seen in Fig. 11a. The time- and domain-averaged vertical-velocity variance is $0.31 \mathrm{~m}^{2} \mathrm{~s}^{-2}$ in the control run, while it is $0.20 \mathrm{~m}^{2} \mathrm{~s}^{-2}$ in the control-no-adv run. Hence, there is $\sim 35 \%$ decrease in the variance in the control-no-adv run as compared to that in the control run. As seen in Fig. 12, in general, no advection of cold air raises temperature, while no 
(a) Potential temperature

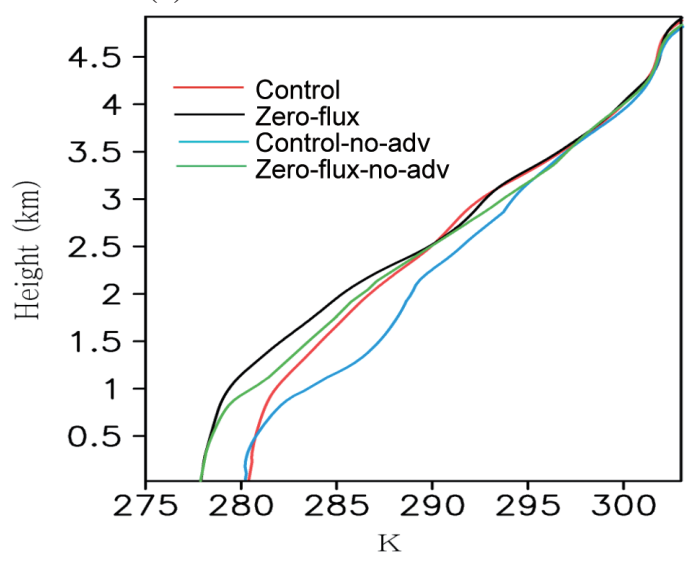

(b) Water vapor

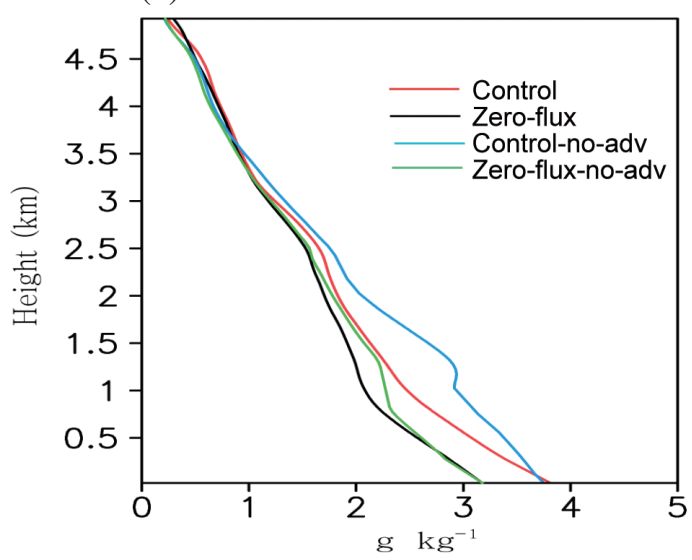

Fig. 12. Vertical distributions of the time- and domain-averaged (a) potential temperature (K) and (b) water-vapor mixing ratio $\left(\mathrm{g} \mathrm{kg}^{-1}\right)$.

Table 4. The time- and domain-averaged

CAPE.

\begin{tabular}{cc}
\hline Simulations & CAPE $\left(\mathbf{J ~ k g}^{-1}\right)$ \\
\hline Control run & 680.2 \\
Zero-flux run & 150.3 \\
Control-no-adv run & 500.7 \\
Zero-flux-no-adv run & 120.5 \\
\hline
\end{tabular}

advection of dry air raises humidity as compared to those in the control run. However, near the surface, there are nearly no changes in temperature and humidity between the control run and the control-no-adv run, which is contrary to the overall situation above the surface. This is because increases in temperature and humidity due to the absence of low-level advection are offset by decreases in surface heat fluxes. The absence of advection of cold and dry air leads to smaller contrast in temperature and humidity between the surface and the atmosphere immediately above it, which in turn leads to smaller surface heat fluxes.

The increase in temperature due to the low-level advection removed induces larger averaged increases in temperature per unit height in the control-no-adv run than in the control run and in the zero-flux run. The averaged rate of increase in temperature is $4.1 \times 10^{-3} \mathrm{~K} \mathrm{~m}^{-1}$ below $2 \mathrm{~km}$ in the control-no-adv run, which is larger than in the control run and the zero-flux run. Associated with this, the timeand domain-averaged CAPE is higher in the control run $\left(680.2 \mathrm{~J} \mathrm{~kg}^{-1}\right)$ than in the control-no-adv run $\left(500.7 \mathrm{~J} \mathrm{~kg}^{-1}\right)$ (Table 4). It is interesting that CAPE is smaller in the zeroflux run than in the control-no-adv run despite the larger rate of the increases in temperature in the control-no-adv run than in the zero-flux run. The time- and domain-averaged CAPE is 150.3 and $500.7 \mathrm{~J} \mathrm{~kg}^{-1}$ in the zero-flux run and in the control-no-adv run, respectively (Table 4). This is because the decrease in temperature around the surface in the zero-flux run (as compared to that in the control-no-adv run as seen in Fig. 12) causes CAPE in the zero-flux run to be much smaller than that in the control-no-adv run. It is notable that there is the much larger decrease in CAPE in the zero-flux run than in the control-no-adv run as compared to CAPE in the control run. This indicates that the decreases in the surface temperature play a much more critical role in the decrease in CAPE than the enhancement in the rate of the increases in temperature with height.

The reduced CAPE leads to reduced updrafts, thus, reduced deposition, and the amount of snow which reaches the surface in the control-no-adv run as compared to those in the control run (Fig. 11a and Table 3). However, associated with much smaller decreases in CAPE in the controlno-adv run than in the zero-flux run (as compared to CAPE in the control run), this reduction in the control-no-adv run is much smaller than that in the zero-flux run.

Results in the control-no-adv run as compared to those in the control run and the zero-flux run indicate that the effect of the advection on snowfall is much weaker than that of surface heat fluxes. This indicates that focusing only on the advection as adopted by previous studies is not able to explain heavy snowfall and we need to take additional attention to surface fluxes for the better understanding of heavy snowfall. 


\subsection{Zero-Flux-No-Adv Run}

To confirm the findings of much less important roles played by the advection of cold and dry air on snowfall than those by surface heat fluxes, the control run is repeated again with both the negative large-scale forcings of temperature and humidity and surface heat fluxes set at 0 . This run is referred to as the zero-flux-no-adv run. In the perspective of the zero-flux run, the zero-flux-no-adv run is a simulation where the negative forcings are set at 0 in addition to surface heat fluxes. In the perspective of the control-no-adv run, the zero-flux-no-adv run is a simulation where surface heat fluxes are set at 0 in addition to the negative forcings. The comparison of snowfall between the zero-flux run and the zero-flux-no-adv run shows that there are no significant differences in snowfall between these two runs (Fig. 4). The domain-averaged cumulative precipitation (most of which is composed of snow) at the last time step is 1.9 and $1.5 \mathrm{~mm}$ in the zero-flux run and the zero-flux-no-adv run, respectively. Since surface heat fluxes are set at 0 for both of these two runs and the negative forcings vary between them, the variation in the domain-averaged cumulative precipitation is caused by the variation of negative forcings but not by that of surface fluxes between the runs.

The comparison of snowfall between the control-noadv run and the zero-flux-no-adv run shows that there are significant decreases in snowfall from the control-no-adv run to the zero-flux-no-adv run. The domain-averaged cumulative precipitation (most of which is composed of snow) at the last time step is 9.8 and $1.5 \mathrm{~mm}$ in the control-noadv run and the zero-flux-no-adv run, respectively. Since the negative forcings are set at 0 for both of these two runs and surface fluxes vary between them, the variation in the domain-averaged cumulative precipitation is caused by the variation of surface fluxes but not by that of the negative forcings between the runs. These isolated roles by surface fluxes in cumulative precipitation (between the control-noadv run and the zero-flux-no-adv run) as compared to those by the negative forcings (between the zero-flux run and the zero-flux-no-adv run) confirm that the removal of the negative forcings does not affect snowfall much, while the removal of surface heat fluxes affect snowfall significantly.

When the low-level advection is additionally set at 0 in the zero-flux-no-adv run (in the perspective of the zero-flux run), in general, temperature and humidity increase below $\sim 2 \mathrm{~km}$ due to the absence of cold and dry air coming into the domain as compared to the zero-flux run (Fig. 12). However, around the surface, there are no significant differences in temperature and humidity between the zero-flux run and the zero-flux-no-adv run due to no differences in surface heat fluxes, which leads to slightly larger stability in the zeroflux-no-adv run than in the zero-flux run. The zero-flux-noadv run has CAPE of $120.5 \mathrm{~J} \mathrm{~kg}^{-1}$, while the zero-flux run has CAPE of $150.3 \mathrm{~J} \mathrm{~kg}^{-1}$ (Table 4).
When surface heat fluxes are additionally set at 0 in the zero-flux-no-adv run (in the perspective of the control-noadv run), in general, temperature and humidity decrease below $\sim 2 \mathrm{~km}$ as compared to the control-no-adv run (Fig. 12). This is mainly due to the absence of the supply of heat and moisture by surface heat fluxes into the atmosphere. This reduction in temperature and humidity below $\sim 2 \mathrm{~km}$ including places around the surface leads to substantial decreases in CAPE as compared to that in the control-no-adv run. CAPE for the zero-flux-no-adv run is $120.5 \mathrm{~J} \mathrm{~kg}^{-1}$, while it is $500.7 \mathrm{~J} \mathrm{~kg}^{-1}$ for the control-no-adv run (Table 4).

Associated with the large CAPE variations, there is a large variation of the vertical-velocity variance between the control-no-adv run and the zero-flux-no-adv run (Fig. 11a). The time- and domain-averaged vertical-velocity variance is $0.20 \mathrm{~m}^{2} \mathrm{~s}^{-2}$ in the control-no-adv run, while it is $0.05 \mathrm{~m}^{2} \mathrm{~s}^{-2}$ in the zero-flux-no-adv run. Hence, the variance is 4 times smaller in the zero-flux-no-adv run as compared to that in the control-no-adv run. Associated with the small CAPE variations, there is a small variation of the variance between the zero-flux run and the zero-flux-no-adv run (Fig. 11a). The time- and domain-averaged vertical-velocity variance is $0.07 \mathrm{~m}^{2} \mathrm{~s}^{-2}$ in the zero-flux run, while it is $0.05 \mathrm{~m}^{2} \mathrm{~s}^{-2}$ in the zero-flux-no-adv run. Hence, there is $\sim 30 \%$ difference in the variance between the zero-flux run and the zero-flux-noadv run. Related to the small variation of updrafts, there are no significant changes in deposition between the zero-flux run and the zero-flux-no-adv run (Table 3 ). This eventually results in the negligible variation of cumulative snowfall between the zero-flux run and the zero-flux-no-adv run. Related to the large variation of updrafts, there are significant changes in deposition and cumulative snowfall between the control-no-adv run and the zero-flux-no-adv run (Table 3).

\subsection{Dependence on Initial Conditions}

It is hypothesized that roles played by the advection of cold and dry air in clouds and their vertical-velocity variance can be more critical during the pre-snowfall period than the snowfall period. To examine this hypothesis, we repeat the four runs (i.e., the control run, the zero-flux run, the control-no-adv run, and zero-flux-no-adv run) by including the pre-snowfall period, which is before 03:00 LST 20 March, in the simulation period. To include the pre-snowfall period, the initial time of the simulation period is altered from 03:00 LST 20 March to 21:00 LST 19 March in the repeated runs. Thus, for these repeated runs, the initial conditions are at 21:00 LST 19 March and the simulation period is only for the pre-snowfall period between 21:00 LST 19 March and 03:00 LST 20 March. The first three hours are considered a spin-up period, hence, the analyses on the repeated runs are performed for a 3-hr period between 00:00 LST and 03:00 LST 20 March. Analyses on the repeated runs show that the qualitative nature of results does not vary with the varying 
initial time of the simulation period or initial conditions. This is demonstrated by comparisons between Fig. 11c that shows the averaged vertical-velocity variance over the 3 -hr period in the repeated runs and Fig. 11a that shows the variance in the four runs whose initial time is at 03:00 LST 20 March.

\section{SUMMARY AND CONCLUSIONS}

Comparisons among the sensitivity simulations (i.e., the zero-flux and the control-no-adv runs) and the standard simulation (i.e., the control run) demonstrate that the effects of surface heat fluxes play a far more important role in heavy snowfalls than those of the advection of cold and dry air. The absence of the advection raises the atmospheric temperature and humidity but around the surface, there are negligible changes in temperature and humidity due to competitions between changes in surface heat fluxes and those in the atmospheric temperature and humidity. The absence of surface heat fluxes lower the temperature and humidity in the places including those around the surface. Especially, the decreases in the temperature and humidity around the surface lead to far smaller CAPE, which in turn leads to much smaller updrafts, deposition and snowfall in the simulation with surface fluxes set to 0 than in the standard run. Of interest is that although there is a decrease in CAPE in the simulation with the absence of the advection (as compared to CAPE in the standard run), the negligible changes in temperature and humidity around the surface lead to a situation where the CAPE decrease with the absence of advection is much smaller than that with the absence of surface heat fluxes. Hence, the decrease in snowfall with the absence of advection as compared to snowfall in the standard run is much smaller than that with the absence of the surface fluxes. Comparisons between these two sensitivity simulations and the simulation with the absence of both surface fluxes and advection confirm much more important roles by surface fluxes than those by the advection.

At least for the case simulated here, this study indicates that just focusing on the advection of cold and dry air as in the previous studies of snowfalls in the eastern coast of Korea is not sufficient for the comprehensive understanding of mechanisms that control heavy snowfall. The findings of this study demonstrate that we may have to take attention to the surface processes related to surface heat fluxes for the comprehensive understanding. It has been difficult to measure up surface fluxes particularly over the ocean and this is why previous observational studies have been mainly focusing on the atmospheric temperature, humidity and stability (related to the advection of cold and dry air) that can be easily measured to investigate heavy snowfalls in the eastern coast of Korea. This study suggests that we should develop a plan to observe the surface processes and associated surface heat fluxes for the comprehensive understanding.

Here, we want to emphasize that depending on the synoptic situation where clouds are embedded, cloud types, the advection of cold and dry air and surface heat fluxes can vary and the relative importance between the advection and surface heat fluxes for heavy snowfalls can vary. For example, it is possible to have a synoptic situation where the advection is much stronger and surface fluxes are much weaker as compared to those in the synoptic situation where the simulated clouds in this study are embedded. In this synoptic situation, the contribution of surface heat fluxes to instability (or CAPE) may not be as great as that in the simulated clouds in this study, while the advection can make a greater contribution to instability than that in the simulated clouds in this study. This can lead to more important roles played by the advection than by surface heat fluxes in the production of heavy snowfalls. Also, it is possible to have a synoptic condition that favors the neutral stability and stratus clouds that produce heavy snowfalls. This possible dependence of relative importance between the advection and surface heat fluxes and cloud types on the synoptic conditions and the role by the dependence in heavy snowfalls merits further studies.

Acknowledgements This study was supported by the Korean Meteorological Administration Research and Development Program (CATER 2012-6050) and Basic Science Research Program through the National Research Foundation of Korea (NRF) funded by the Ministry of Education, Science and Technology (2010-0211 and No. 2012R1A1A2001133 and 2015R1D1A1A09059906). This study was also supported by Development of Climate and Atmospheric Environmental Applications project, funded by ETRI, which is a subproject of Development of Geostationary Meteorological Satellite Ground Segment (NMSC-2017-01) program funded by NMSC of KMA, and Research and Development for KMA Weather, Climate, and Earth system Services (NIMS-20163100) of the National Institute of Meteorological Sciences (NIMS) funded by the Korea Meteorological Administration (KMA). Additional support was provided by the Korea Meteorological Administration Research and Development Program "Research and Development for KMA Weather, Climate, and Earth system Services-Support to Use of Meteorological Information and Value Creation" under Grant (KMA2018-00222).

\section{REFERENCES}

Abdul-Razzak, H. and S. J. Ghan, 2000: A parameterization of aerosol activation: 2. Multiple aerosol types. J. Geophys. Res., 105, 6837-6844, doi: 10.1029/1999JD901161. [Link]

Abdul-Razzak, H. and S. J. Ghan, 2002: A parameterization of aerosol activation 3. Sectional representation. $J$. Geophys.Res.,107,4026, doi: 10.1029/2001JD000483. [Link] 
Ahn, J. B. and E. H. Cho, 1998: Atmospheric mesoscale model responses to given sea-surface temperature around Korea peninsula. Kor. J. Atmos. Sci., 34, 643651.

Chen, F. and J. Dudhia, 2001: Coupling an Advanced Land Surface-Hydrology Model with the Penn State-NCAR MM5 Modeling System. Part I: Model Implementation and Sensitivity. Mon. Weather Rev., 129, 569-585, doi: 10.1175/1520-0493(2001)129<0587:CAALSH >2 .0.C O;2. [Link]

Choi, G. Y. and J. S. Kim, 2010: Surface synoptic climatic patterns for heavy snowfall events in the republic of Korea. J. Korean geogr. Soc., 45, 319-341.

Donner, L. J., C. J. Seman, and R. S. Hemler, 1999: Threedimensional cloud-system modeling of GATE convection. J.Atmos. Sci., 56, 1885-1912, doi: 10.1175/15200469(1999)056<1885:TDCSMO>2.0.CO;2. [Link]

Houze, R. A., 1993: Cloud Dynamics, Academic Press, 573 pp, doi: 10.1016/s0074-6142(08)x6050-4. [Link]

Kim, J.E. and T. Y. Kwon, 2005: Characteristics of sensible heat fluxes over the East Sea related with Yeongdong heavy snowfall events. Ocean and Polar Res., 27, 237250, doi: 10.4217/OPR.2005.27.3.237. [Link]

Kim, J. H., S. S. Yum, S. Shim, W. J. Kim, M. Park, J.-H. Kim, M.-H. Kim, and S.-C. Yoon, 2014: On the submicron aerosol distributions and $\mathrm{CCN}$ number concentrations in and around the Korean Peninsula. Atmos. Chem. Phys., 14, 8763-8779, doi: 10.5194/acp-148763-2014. [Link]

Lee, J. G. and J. S. Sung, 2003: A numerical study of Yeongdong heavy snowfall events associated with easterly. Atmosphere, 39, 475-490.

Lee, S. S., L. J. Donner, V. T. J. Phillips, and Y. Ming, 2008: The dependence of aerosol effects on clouds and precipitation on cloud-system organization, shear and stability. J. Geophys. Res., 113, D16202, doi: 10.1029/2007JD009224. [Link]

Lee, S. S., L. J. Donner, and J. E. Penner, 2010: Thunderstorm and stratocumulus: how does their contrasting morphology affect their interactions with aerosols? Atmos. Chem. Phys., 10, 6819-6837, doi: 10.5194/acp10-6819-2010. [Link]

Lee, S. S., G. Feingold, A. McComiskey, T. Yamaguchi, I. Koren, J. V. Martins, and H. Yu, 2014: Effect of gradients in biomass burning aerosol on shallow cumulus convective circulations. J. Geophys. Res., 119, 9948 9964, doi: 10.1002/2014JD021819. [Link]
Liou, K. N., 2002: An Introduction to Atmospheric Radiation, Academic Press, 583 pp, doi: 10.1016/s00746142(02)x8015-2. [Link]

Nakamura, K. and T. Asai, 1985: A numerical experiment of airmass transformation processes over warmer sea. Part II: Interaction between small-scale convections and large-scale flow. J. Meteorol. Soc. Jpn., 63, 805827, doi: 10.2151/jmsj1965.63.5_805. [Link]

Park, J. H., K. E. Kim, and B. H. Heo, 2009: Comparison of development mechanisms of two heavy snowfall events occurred in Yeongnam and Yeongdong regions of the Korean peninsula. Atmosphere, 19, 9-36.

Saleeby, S. M. and W. R. Cotton, 2004: A large-droplet mode and prognostic number concentration of cloud droplets in the Colorado state university regional atmospheric modeling system (RAMS). Part I: Module descriptions and supercell test simulations. J. Appl. Meteorol., 43, 182-195, doi: 10.1175/1520-0450(200 4)043<0182:ALMAPN>2.0.CO;2. [Link]

Seo, E.-K. and J.-G. Jhun, 1991: Study on heavy snowfall between January 29th and February 1st in 1990 in Korean Peninsula. Asia-Pac. J. Atmos. Sci., 27, 165-179.

vanZanten, M. C., B. Stevens, L. Nuijens, A P. Siebesma, A. S. Ackerman, F. Burnet, A. Cheng, F. Couvreux, H. Jiang, M. Khairoutdinov, Y. Kogan, D. C. Lewellen, D. Mechem, K. Nakamura, A. Noda, B. J. Shipway, J. Slawinska, S. Wang, and A. Wyszogrodz$\mathrm{ki}, 2011$ : Controls on precipitation and cloudiness in simulations of trade-wind cumulus as observed during RICO. J. Adv. Model. Earth Syst., 3, M06001, doi: 10.1029/2011MS000056. [Link]

Xu, K.-M., R. T. Cederwall, L. J. Donner, W. W. Grabowski, F. Guichard, D. E. Johnson, M. Khairoutdinov, S. K. Krueger, J. C. Petch, D. A. Randall, C. J. Seman, W.-K. Tao, D. Wang, S. C. Xie, J. J. Yio, and M.-H. Zhang, 2002: An intercomparison of cloudresolving models with the Atmospheric Radiation Measurement summer 1997 Intensive Observation Period data. Q. J. R. Meteorol. Soc., 128, 593-624, doi: 10.1256/003590002321042117. [Link]

Yoshizaki, M., T. Kato, H. Eito, S. Hayashi, and W.-K. Tao, 2004: An overview of the field experiment "Winter mesoscale convective systems (MCSs) over the Japan Sea in 2001", and comparisons of the cold-air outbreak case (14 January) between analysis and a non-hydrostatic cloud-resolving model. J. Meteorol. Soc. Jpn., 82, 1365-1387, doi: 10.2151/jmsj.2004.1365. [Link] 